\title{
Bioactivity of crude ethanol extract and fractions of Eugenia uniflora (Myrtaceae) in the hepatopancreas of Oreochromis niloticus $\mathrm{L}$
}

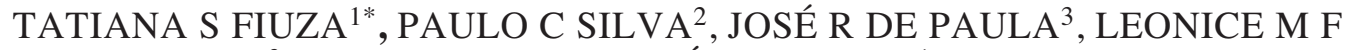 \\ TRESVENZOL ${ }^{3}$ and SIMONE M T SABÓIA-MORAIS ${ }^{1}$
}

${ }^{1}$ Institute of Biological Science.
2 Department of Animal Production, School of Veterinary Medicine.
${ }^{3}$ Faculty of Pharmacy, Federal University of Goiás, Goiânia, GO, Brazil.

\begin{abstract}
This study evaluates the bioactivity of the crude ethanol extract and ethyl acetate, hexane and chloroform fractions obtained from Eugenia uniflora leaves using the hepatopancreas of Oreochromis niloticus L. as an experimental model. The ethanol extract and fractions were administered to the fish orally with their feed. Twenty-four hours later, the fish were sacrificed and their livers dissected, fixed in neutral formalin, embedded in paraffin and sectioned. Histological analyses were performed using Masson's trichrome and Haematoxylin-Eosin. Histochemical studies were performed using Feulgen, PAS (Periodic Acid Schiff) and PAS + salivary amylase and Sudan IV stain. The qualitative analysis of the material showed that the crude extract and the ethyl, chloroform and hexane fractions induced vasodilation, vascular congestion and toxicity due to the presence of eosinophilic granular cells, rodlet cells, some leukocytic infiltrate and rare focal necroses. The Nile tilapia proved to be a satisfactory model for screening plant products.
\end{abstract}

Key terms: fish, medicinal plants, vasodilation.

\section{INTRODUCTION}

The genus Eugenia L. (Myrtaceae) has 14 species, among them Eugenia uniflora L., popular in Brazil for its Surinam cherry. This plant is a tall semi-deciduous tree or bush, reaching a height of $4-10 \mathrm{~m}$ with a smooth light brown trunk (Sano and Almeida, 1998), commonly found in Brazil from the states of Minas Gerais to Rio Grande do Sul (Sanchonete, 1985). It is used in folk medicine as an antihypertensive and diuretic drug (Consolini and Sarubbio, 2002); as an astringent, for the treatment of digestive disorders (Bandoni et al., 1972) and as an antipyretic, anti-rheumatic (Alice et al., 1991) and antimicrobial drug (Souza et al., 2004). On Madeira Island Eugenia uniflora L. leaves are used to treat bronchitis, influenza and intestinal disorders, and in Nigeria they are also used as an antipyretic drug (Consolini and Sarubbio, 2002). Pharmacological testing of the leaf extract of E. uniflora indicates a reduction in blood pressure measured by direct vasodilation and slight diuretic effect which could be due to an increase in renal blood flow (Consolini et al., 1999).

There are no detailed studies in the literature regarding the possible cellular effects and/or toxicity of the crude ethanol extract and fractions of E. uniflora. To obtain data on the cytotoxicology and cellular and vascular effects of the extract from this plant, the teleostean Nile tilapia (Oreochromis niloticus L.) was used as an experimental model.

\footnotetext{
* Corresponding Author: Dra Tatiana de Sousa Fiuza, Instituto de Ciências Biológicas, - ICB III - Universidade Federal de Goiás C.P. 131 - 74001-970, Goiânia - GO, Brazil. Tel: +5562 99882324; Fax: +55 62 3521-1109, E-mail: tatianaanatomia@gmail.com
}

Received: August 6, 2008. In Revised form: July 19, 2009. Accepted: August 20, 2009. 
The Nile tilapia (Oreochromis niloticus L) is one of the various species of teleostean fish used in experimental research. Originally from the Ivory Coast in Africa, it was brought to Pentecoste in the state of Ceará in Brazil by the National Department for Drought Prevention Departamento Nacional de Obras Contra a Seca (D.N.O.C.S) (Castagnolli, 1992). The normal Nile tilapia liver is composed of hexagonal hepatic cells, with a centrally or excentrally located nucleus and homogenous cytoplasm (El-Elaimy et al., 1993). The exocrine pancreatic tissue in this fish is generally found inside the hepatic tissue and located around the blood vessels; therefore the liver is referred to as the hepatopancreas (El-Elaimy et al., 1993).

The purpose of this study was (1) to test the bioactivity of the crude ethanol extract and the ethyl acetate, hexane and chloroform fractions, obtained from $E$. uniflora leaves in the hepatopancreas of Oreochromis niloticus Linnaeus, (2) to verify the effects on vessels, cells and others tissues, (3) to establish the Nile tilapia as an experimental model for the study of plant extracts and fractions.

\section{MATERIAL AND METHODS}

\section{Material}

Leaves from the Eugenia uniflora species were collected in the municipality of Goiânia, Goiás (16 $36^{\circ} 15$, 1' S e $49^{\circ} 16^{\prime} 0$, 70 " W, at $778 \mathrm{~m}$ altitude) between February and April 2005, identified by Professor Dr. José Realino de Paula from the Federal University of Goiás. A voucher specimen was deposited at the herbarium of that institution under registration number UFG/ 29859. The leaves from the Eugenia uniflora species were oven desiccated at $40^{\circ} \mathrm{C}$ and subsequently ground in a knife mill.

\section{Preparation of the crude ethanol extract and fractions}

The E. uniflora leaf powder was extracted using ethanol $96 \%$ at room temperature until exhaustion and concentrated in a rota evaporator at $40^{\circ} \mathrm{C}$.

The fractions were obtained by dissolving the crude ethanol extract in methanol and then adding distilled water until a $\mathrm{MeOH} / \mathrm{H}_{2} \mathrm{O}$ 7: 3 solution was reached. The resulting solution was then extracted three times in succession with hexane, chloroform and ethyl acetate. The hexane, chloroform and ethyl acetate fractions were concentrated in a rota evaporator at $40^{\circ} \mathrm{C}$ (Ferri, 1996).

\section{Experimental model}

The experiment was carried out from March through June 2007. The male Nile tilapias $(n=55)$ were obtained from the Fish Culture section of the School of Veterinary Medicine in the Federal University of Goiás. The fish were weighed and kept in $100 \mathrm{~L}$ tanks supplied with well-aired water at a proportion of $100 \mathrm{~L}$ per hour (Raceway system) and fed a commercial extruded feed 4 to $6 \mathrm{~mm}$ in diameter containing $32 \%$ protein twice daily at 9 a.m. and 4 p.m. Each fish was kept in a box with two smaller specimens for one week before the experiment, in order to adapt to the new environment.

Every week $\mathrm{pH}$, temperature and ammonia and oxygen content in the water were measured with an Alfakit Card Kit (Brazil).

In the experiment performed, the total ammonia content in the water remained constant at $0.5 \mathrm{mgL}-1$, the $\mathrm{O}_{2}$ content varied from 5.9 to $6.5 \mathrm{mg} \mathrm{O} \mathrm{O}_{2} \mathrm{~L}-1$ and water temperature varied from $19.5^{\circ} \mathrm{C}$ to $26^{\circ} \mathrm{C}$.

The feed containing extracts and fractions was prepared one day before the experiment. Extracts and fractions were calculated according to animal weight, diluted in $96 \%$ ethanol and mixed with previously weighed feed. The ethanol was exposed to an air current for 24 hours for evaporation, before diet administration. After total ethanol evaporation, the feed was weighed once again. The number of pellets containing the crude extract and fractions was calculated according to the daily pellet consumption by the fish during the adaptation week. On the day of 
the experiment an average of 2 to 3 pellets containing the $E$. uniflora crude extract or fractions were administered to each fish. The animals were then fed normally.

For the experimental analysis, eleven groups of five fish were placed in separate containers. The animals weighed on average $229 \mathrm{~g} \pm 57.8 \mathrm{~g}$ and measured 19.8 $\mathrm{cm}$ to $26.5 \mathrm{~cm}$. Group one received 280 $\mathrm{mgkg}^{-1}$ of the crude ethanol extract; group two received $70 \mathrm{mgkg}^{-1}$ of the hexane fraction, group three received $140 \mathrm{mgkg}^{-1}$ of the hexane fraction, group four received $280 \mathrm{mgkg}^{-1}$ of the hexane fraction; group five received $70 \mathrm{mgkg}^{-1}$ of the chloroform fraction, group six received $140 \mathrm{mgkg}^{-1}$ of the chloroform fraction, group seven received $280 \mathrm{mgkg}^{-1}$ the chloroform fraction, while group eight received 70 $\mathrm{mgkg}^{-1}$ of the ethyl acetate fraction, group nine received $140 \mathrm{mgkg}^{-1}$ of the ethyl acetate fraction and group ten received $280 \mathrm{mg} / \mathrm{kg}$ of the ethyl acetate fraction. The control group (group eleven) received feed only immersed in ethanol and evaporated under an air current for 24 hours

Twenty-four hours after treatment, the fish were desensitized by hypothermia in water and ice at a 1: 1 proportion (method recommended by the Brazilian Ministry of Agriculture, 1995) and then rapidly decapitated. The livers were dissected, fixed in neutral formalin and dehydrated, then embedded in paraffin, and sectioned (3 $\mu \mathrm{m}$ thickness). Masson's trichrome and Haematoxylin-Eosin (HE) stains were applied for histological analysis. The following staining procedures were performed for histochemical evaluation: Feulgen [1N hydrochloric acid $60^{\circ} \mathrm{C}$; Schiff's reagent; sulfurous rinse $(10 \%$ sodium metabisulfite $+1 \mathrm{~N}$ hydrochloric acid)] for DNA detection, PAS (0.5\% periodic acid solution) and $\mathrm{PAS}+$ salivary amylase for glycol conjugate detection and Sudan IV (0.1\% nuclear fast red) for lipid identification, where the fragments of fresh fish liver were frozen and sectioned at $10 \mu \mathrm{m}$ thickness and stained. Subsequently the sections were dehydrated and the coverslips mounted in Entelan
(Merck -USA). The qualitative analysis was performed with a light microscope and images recorded using an Olympus CH-30 photomicroscope.

The experiments described were performed in accordance with the ethical principles for animal research determined by the Brazilian Collegiate for Animal Experimentation (COBEA).

\section{RESULTS}

\section{Macroscopic analyses}

None of the fish died during the experiment. The livers of Nile tilapia treated with the crude extract and fractions presented their normal anatomical appearance. Only the fish submitted to the chloroform and ethyl acetate fractions presented blood vessel dilation and blood congestion.

\section{Light microscopy}

\section{Hepatopancreas - control group}

The livers of the control group appeared normal. The hepatocytes were polyhedral, with central or sub central nuclei arranged in two cell rows bordered by sinusoids. The sinusoids emerged from the central vein in radial distribution, often star shaped. Some rodlet cells (RCs) were noted around the veins. P-VT (pancreaticvenous tract) (Fig. 1a), P-VBT (pancreaticvenous biliary tract) (Fig. 1b), P-VAT (pancreatic-venous arteriolar tract) (Fig. 1c) and P-VBAT (pancreatic-venous biliary arteriolar tract) were noted among the hepatocytes characterizing the liver as a hepatopancreas. The pancreocytes could be seen as islets with their own lamellar lining surrounding the central vein, presenting nuclei in the basal portion of the cell and orangey granules in the apical region when stained with Masson's trichrome (Fig. 1a). Under hematoxylin and eosin (HE), the basal portion of the pancreocytes was basophilic and the granules in the apical region were eosinophilic. 
A few eosinophilic granular cells (EGCs) (Figs. 1a and 1c), rodlet cells (RCs) and occasionally adipocytes and polimorphonuclear cells (PMs) could be seen attached to the external surface of the hepatopancreas.

Capillaries containing erythrocytes were noted amongst the pancreocytes. The veins presented endothelial cells and a few erythrocytes in their interior under Masson's trichrome and HE. Most ducts were joined to the pancreocytes by an outer layer consisting of smooth muscle fibers, a middle layer rich in collagen and a simple ciliated cylindrical epithelium (larger ducts) (Fig. 1b) and a simple cuboid epithelium (smaller ducts) limiting light.

Micronuclei were not diagnosed in any of the groups treated when submitted to the Feulgen reactive analysis. In general the pancreocyte cytoplasm was PAS positive and amylase resistant, therefore containing neutral glycoproteins and occasionally glycogen. Droplets of fat were noted inside the hepatocytes when Sudan IV staining was applied.
Under normal conditions, the hepatocytes present a vacuolized aspect due to cytoplasmic inclusions (glycogen and lipid droplets).

\section{Hepatopancreas after treatment with crude ethanol extract}

The following were noted in the livers of the tilapias treated with the E. uniflora crude extract: P-VAT with various RCs and EGCs (some granulating) among the pancreocytes, attached adipocytes and centroacinar cell in the exocrine pancreas (Fig. 2a). The pancreocytes were vacuolized and the hepatocytes exhibited swelling and irregular walls with some ruptures. Greenish pigments could be seen in the interior of some hepatocytes, while blood vessel dilation (Fig. 2b), blood congested veins (Figs. 2b and 2c), granulating EGCs (Fig. 2d), rare RCs in the middle layer of veins and the presence of focal necrosis (Fig. 2e) were also noted. Isolated biliary ducts with a simple cuboid epithelium and ducts with a simple cylindrical epithelium with fragmented cilia
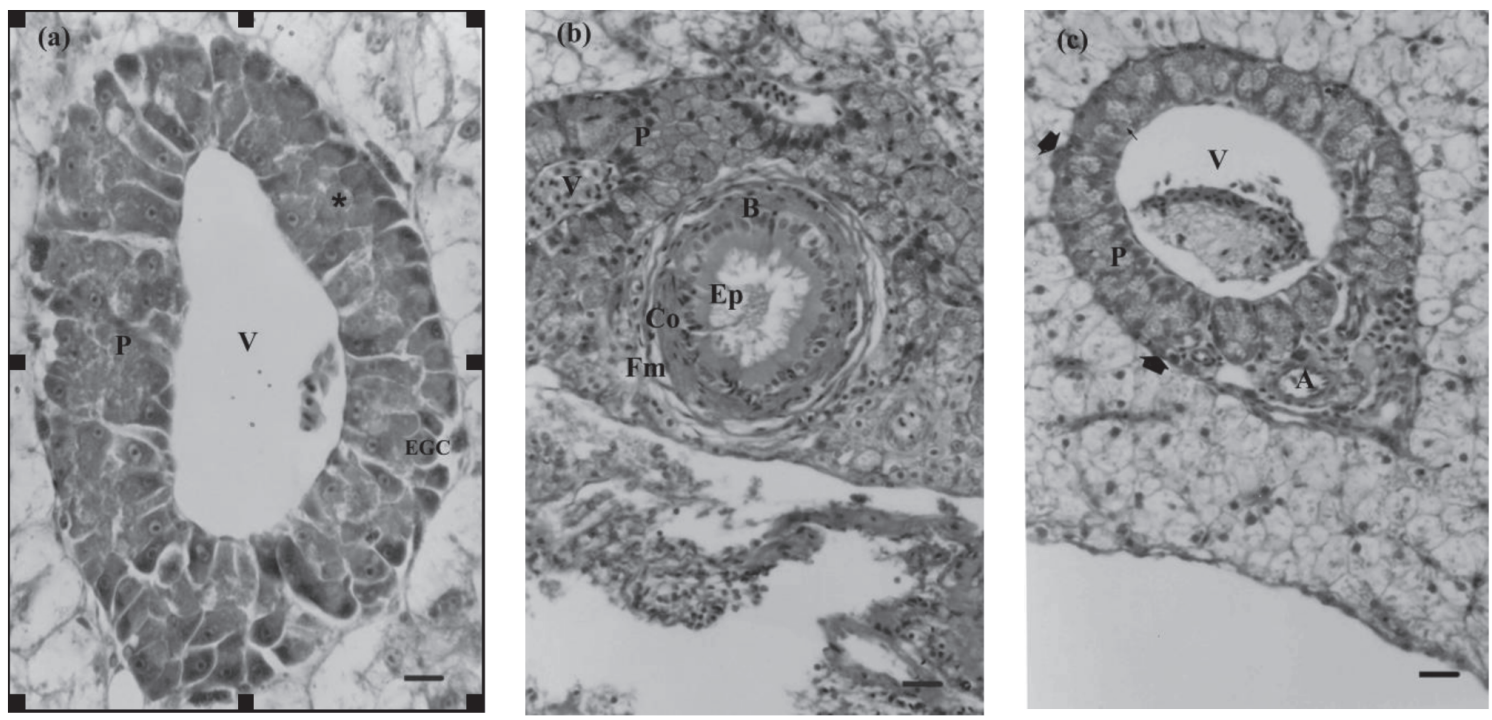

Figure 1: Control group of fish. (a) PVT. Pancreocytes with orangish granules and associated EGCs (Masson's trichrome). (b) P-VBT. Central duct with ciliated cylindrical epithelium (HE). (c) $\mathrm{P}-\mathrm{VAT}$. Presence of EGCS associated to pancreocytes (arrow) (HE). V = vein; $\mathrm{P}=$ pancreocyte; $\mathrm{EGC}=$ eosinophilic granular cell; $\mathrm{Fm}=$ muscle fiber; $\mathrm{Co}=$ collagen; $\mathrm{Ep}=$ epithelium; $\mathrm{B}=$ biliary duct; $\mathrm{A}=$ arteriole. $\mathrm{Bar}=50 \mu \mathrm{m}$. 
(Fig. 2f) attached to the pancreocytes were also detected.

\section{Analysis of Hepatopancreas after treatment with the ethyl acetate fraction}

In the hepatic sections from the tilapia livers treated with $70 \mathrm{mgkg}^{-1}, 140 \mathrm{mgkg}^{-1}$ and $280 \mathrm{mgkg}^{-1}$ of the ethyl acetate fraction, swollen vacuolized hepatocytes were noted, with irregular walls and central nuclei, a few presenting wall ruptures in some regions (Fig. 3a). Focal necrosis was noted in the hepatic parenchyma in the tilapia livers treated with $140 \mathrm{mgkg}^{-1}$.
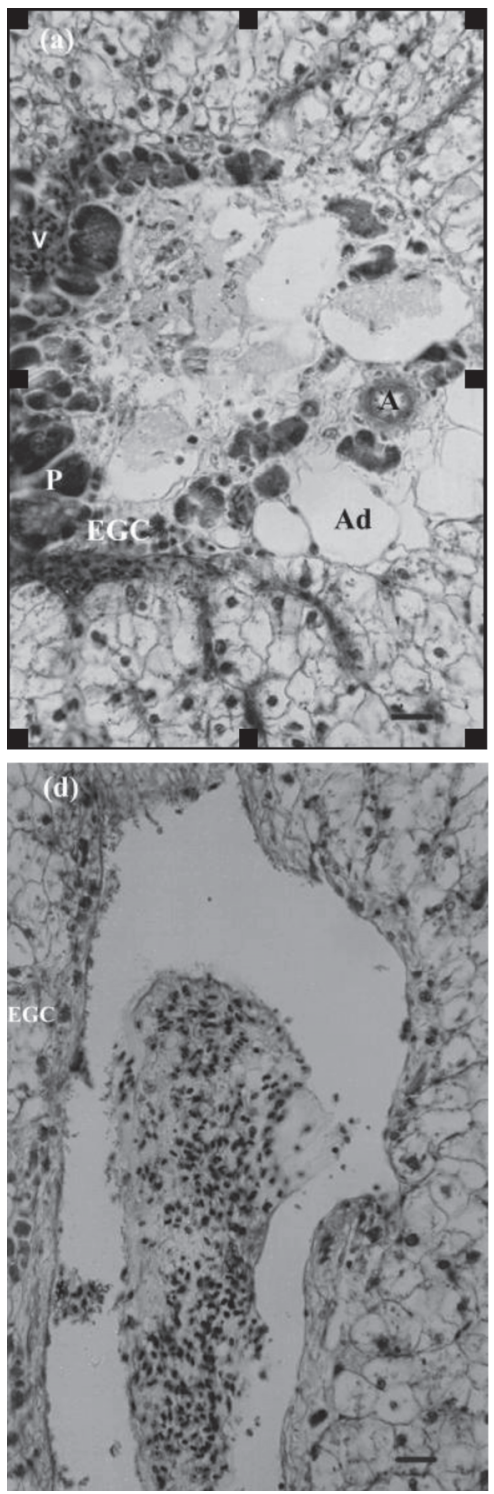
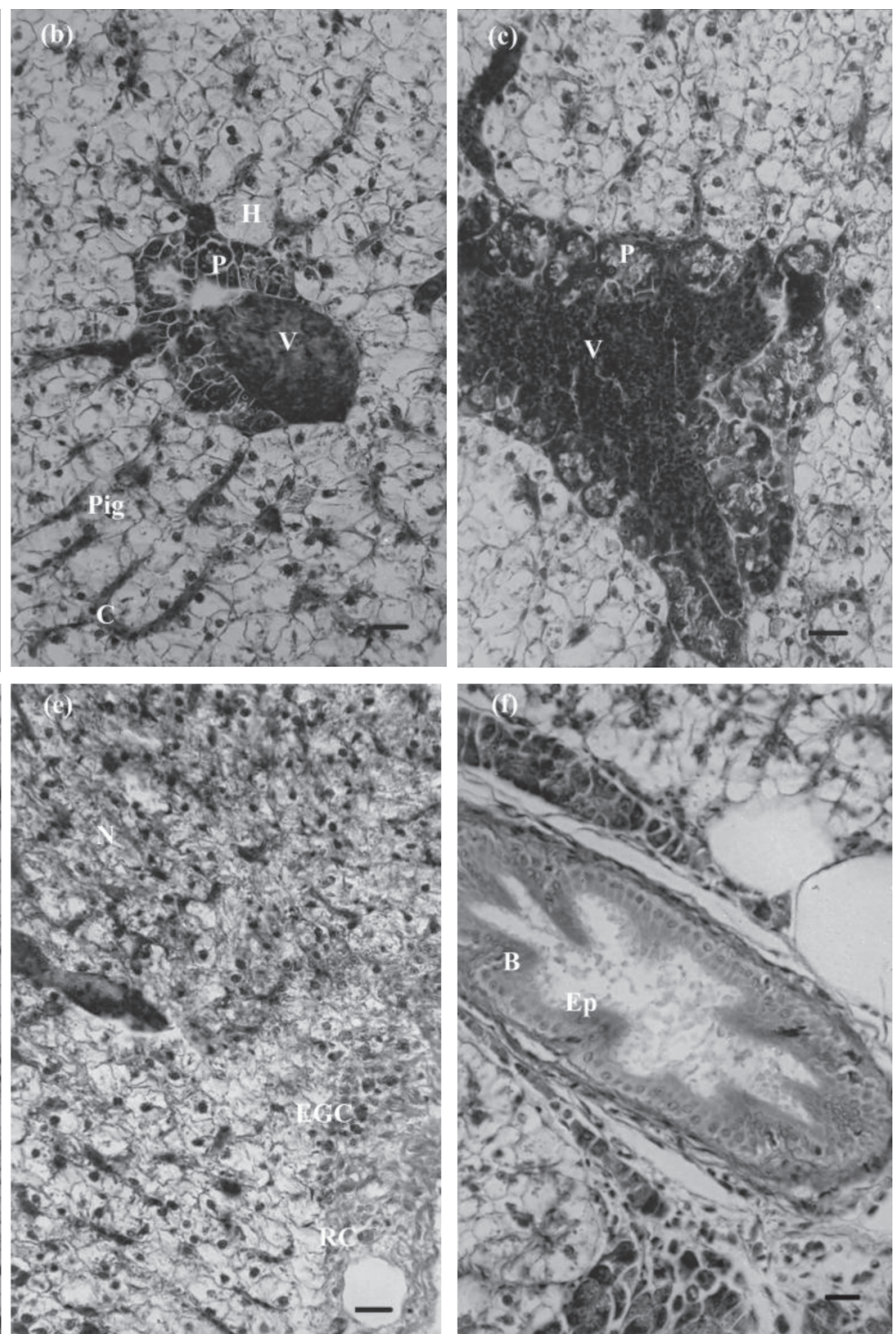

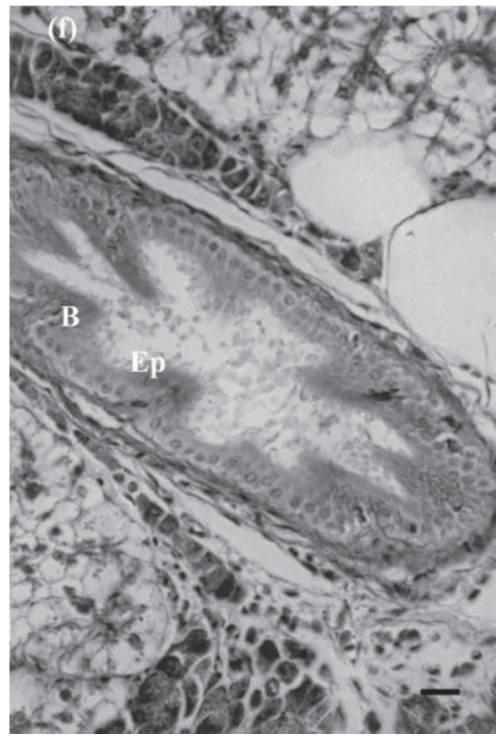

Figure 2: Hepatic sections of fish treated with $280 \mathrm{mgkg}^{-1}$ of crude extract. (a) P-VAT. EGCS and adipocytes associated to pancreocytes. (b) Greenish pigment within the hepatocyte, dilated and congested vessels. (c) Blood congested vein surrounded by pancreocytes. (d) Various EGCs, some degranulating in the middle layer of the vein. (e) Necrosis spot and RC and EGCs in the middle layer of the vein. (f) P-BT. Biliary duct with simple cylindrical epithelium with fragmented cilia. $\mathrm{Ad}=$ adipocyte $\mathrm{A}=$ arteriole $; \mathrm{V}=$ vein $\mathrm{EGC}=$ eosinophilic granular cell $; \mathrm{H}=$ hepatocyte; $\mathrm{P}=$ pancreocyte; $\mathrm{C}=$ capillary; B = biliary duct; $\mathrm{Ep}=$ epithelium. Masson's trichrome. Bar $=50 \mu \mathrm{m}$. 

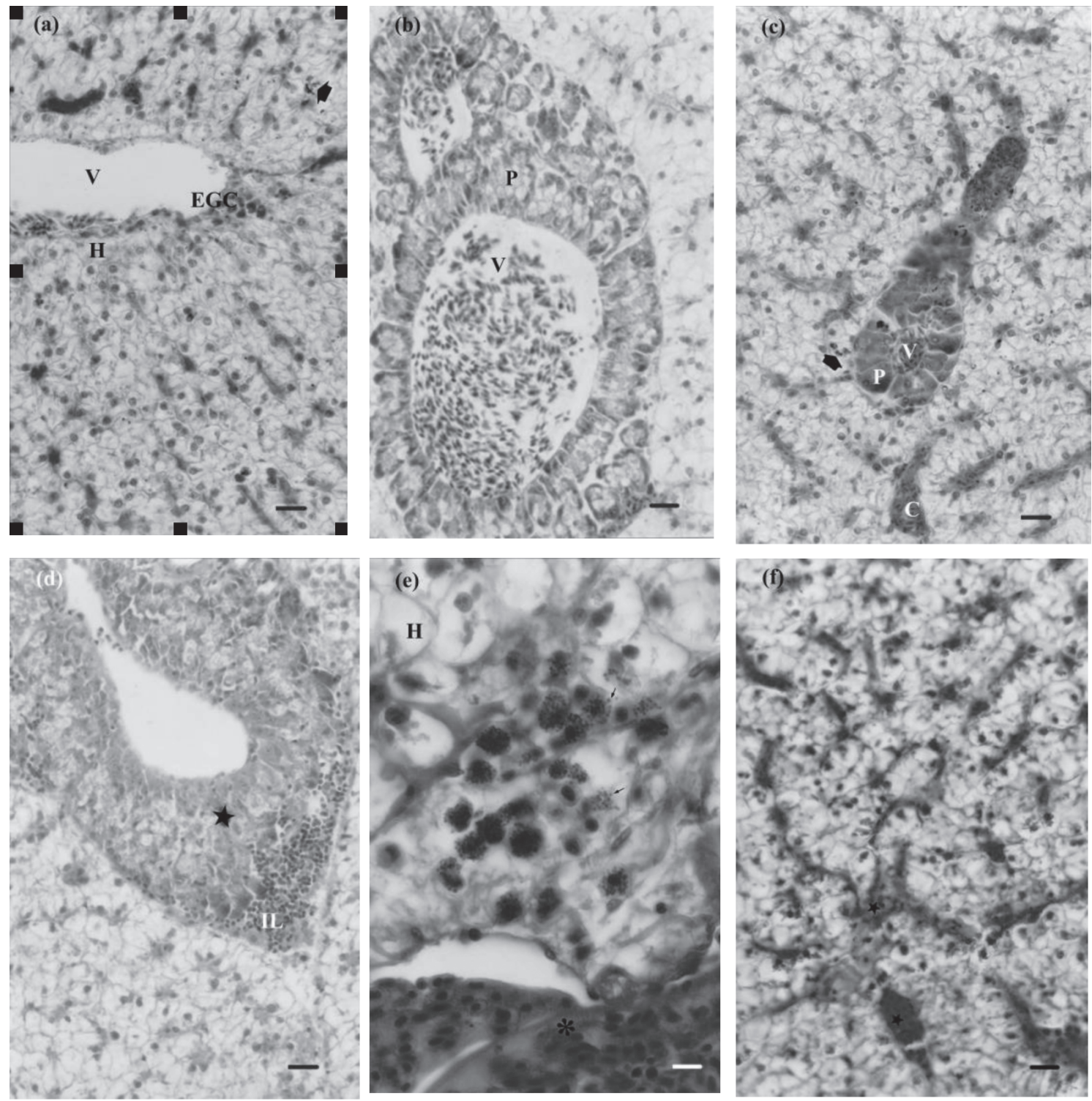

Figure 3: Histological liver cuttings from tilapias which received the ethyl acetate fraction. (a) Vacuolized hepatocytes, with apparent swelling, irregular walls, rupturing, EGCs and aggregated melanomacrophages near the central vein (arrow) $\left(70 \mathrm{mgkg}^{-1}\right)$. (b) Altered pancreocytes with vacuoles in their interior surrounding a vein $\left(140 \mathrm{mgkg}^{-1}\right)$. (c) Melanomacrophages associated to pancreocytes (arrow) $\left(70 \mathrm{mgkg}^{-1}\right)$. (d) Leukocytic infiltrate associated to the pancreas $\left(140 \mathrm{mgkg}^{-1}\right)$. (e) Degranulating EGCs (arrow) $\left(280 \mathrm{mgkg}^{-1}\right)$. (f) Blood vessel dilation and vascular congestion (asterisk) $\left(280 \mathrm{mgkg}^{-1}\right)$. Bar $=50 \mu \mathrm{m}[(\mathrm{a}),(\mathrm{b}),(\mathrm{c}),(\mathrm{d}),(\mathrm{f})]$. Bar $=20 \mu \mathrm{m}$ (e). Masson's trichrome [(a), (b), (c)]. HE [(d), (e), (f)]. $\mathrm{V}=$ vein; $\mathrm{H}=$ hepatocyte; $\mathrm{P}=$ pancreocyte; $\mathrm{C}=$ capillary; $\mathrm{IL}=$ Leukocytic infiltrate.

In all the concentrations the pancreocytes presented morphologic alterations, lack of eosinophil in the apical region, some pancreocytes were intensely liberating their secretion granules to the secretion unit duct, while others presented vacuoles in their interior. Pancreocytes surrounding the central vein were also noted (Fig. 3b).

Aggregated melanomacrophages (MMs) were detected (Fig. 3c), as well as rare RCs attached to the pancreas in the fish that 
received $70 \mathrm{mgkg}^{-1}$ of this fraction and a significant leukocytic infiltrate attached to these cells in the fish that received 140 $\mathrm{mgkg}^{-1}$ (Fig. 3d). Polymorphonuclear cells were noted, especially neutrophiles and degranulated EGCs near the exocrine pancreas and hepatocytes in the fish that received $280 \mathrm{mgkg}^{-1}$ (Fig. 3e).

Liver sections from the tilapias treated with $70 \mathrm{mgkg}^{-1}$ presented vascular congestion accompanied by slight vasodilation, as well as the presence of a few MMs and various EGCs attached to the central vein wall (Fig. 3a). In the other concentrations there was intense blood capillary dilation with vascular congestion (Fig. 3f) and the $140 \mathrm{mgkg}^{-1}$ concentration presented some loss in vein wall delimitation.

Effects of the chloroform fraction on the hepatopancreas

The groups treated with $70 \mathrm{mgkg}^{-1}, 140$ $\mathrm{mgkg}^{-1}$ and $280 \mathrm{mgkg}^{-1}$ presented hepatocyte shrinkage with an eosinophilic aspect (Fig. 4a), some exhibited greenish pigments in their interior. The fish that received the highest concentration also exhibited some hepatocytes with ruptured and rounded walls and in some regions an apparent reduction in the number of hepatocyte nuclei (Fig. 4b).

Altered, vacuolized pancreocytes were diagnosed in all the concentrations with small interior granules, externally limited by a basal membrane surrounding the central vein (Fig. 4b). Leukocytic infiltrate was noted on the pancreatic islets of the fish treated with $70 \mathrm{mgkg}^{-1}$ and EGCs attached to the pancreocytes in the 70 $\mathrm{mgkg}^{-1}$ and $280 \mathrm{mgkg}^{-1}$ specimens (Fig. 4c). The biliary ducts presented different sizes with various EGCs attached in the fish that received the highest and lowest concentrations (Figs. 4b, 4d and 4e). Leukocytic infiltrate and EGCs associated to the central vein were also identified in the $280 \mathrm{mgkg}^{-1}$ concentration.

An increase was noted in the number of sinusoid capillaries among the hepatocytes with congestion and slight vascular dilation in the three groups (Figs. 4a and 4f).

\section{Effects of the hexane fraction on the hepatopancreas}

Rounded more voluminous hepatocytes with irregular walls (some ruptured) and others with internal greenish pigments were noted in the tilapias treated with $70 \mathrm{mgkg}^{-1}, 140 \mathrm{mgkg}^{-}$ 1 and $280 \mathrm{mgkg}^{-1}$ of the hexane fraction (Fig. 5a). An apparent reduction in hepatocyte nuclei was noted with some picnotic nuclei in some regions of the hepatic sections of the animals treated with $140 \mathrm{mgkg}^{-1}$ and 280 $\mathrm{mgkg}^{-1}$ (Fig. 5b). Polymorphonucleated cells with neutrophils and EGCs were spread in the hepatic parenchyma in the $70 \mathrm{mgkg}^{-1}$ group; focal necrosis (Fig. 5c) with the presence of free polymorphonuclears, neutrophils, eosinophils and plasmocytes in the $140 \mathrm{mgkg}^{-}$ 1 group (Fig. 5d) and eosinophilic spots and necrosis with the presence of neutrophils in the $280 \mathrm{mgkg}^{-1}$ group.

Blood congested vessels, dilated capillaries and various EGCs, some degranulating, attached to the veins in the three concentrations, were diagnosed (Fig. $5 b)$.

In the fish that received $280 \mathrm{mgkg}^{-1}$ of the fraction, MMs were identified in veins and hepatocytes as well as a hemorrhagic spot (Fig. 5e). Eosinophilic aspects on the apical surface of the pancreocytes were diagnosed in the $70 \mathrm{mgkg}^{-1}$ and $140 \mathrm{mgkg}^{-1}$ concentrations, as well as the presence of vacuoles, with some cells liberating granules. The fish that received $140 \mathrm{mgkg}^{-1}$ and $280 \mathrm{mgkg}^{-1}$ presented pancreocytes with altered cellular morphology, with a few exhibiting a degenerative aspect, apparent disaggregation in the highest concentration (Fig. 5f) and EGCs, some of which were degranulating, also with attached adipocytes (Fig. 5f).

Biliary ducts of various different diameters were noted in the tilapias treated with $70 \mathrm{mgkg}^{-1}$ and $140 \mathrm{mgkg}^{-1}$ of the hexane fraction, with attached EGCs in the $140 \mathrm{mgkg}^{-1}$ concentration.

\section{DISCUSSION}

Physical and chemical water parameter values in this study were considered 
adequate and/or tolerable by the Nile tilapia since, according to Hein et al. (2004), the ideal water $\mathrm{pH}$ for breeding this fish is between 6.5 and 9.5 ; oxygen content should be between $3 \mathrm{mgL}^{-1}$ and $6 \mathrm{mgL}^{-1}$ and the total ammonia content no higher than 0.5
$\mathrm{mgL}^{-1}$. According to Oetterer (2004), thermal comfort for the tilapia is attained at temperatures from $15^{\circ} \mathrm{C}$ to $35^{\circ} \mathrm{C}$. Therefore, the variation in water temperature from $19.5^{\circ} \mathrm{C}$ to $26^{\circ} \mathrm{C}$ in this study is within the range tolerated by this fish.
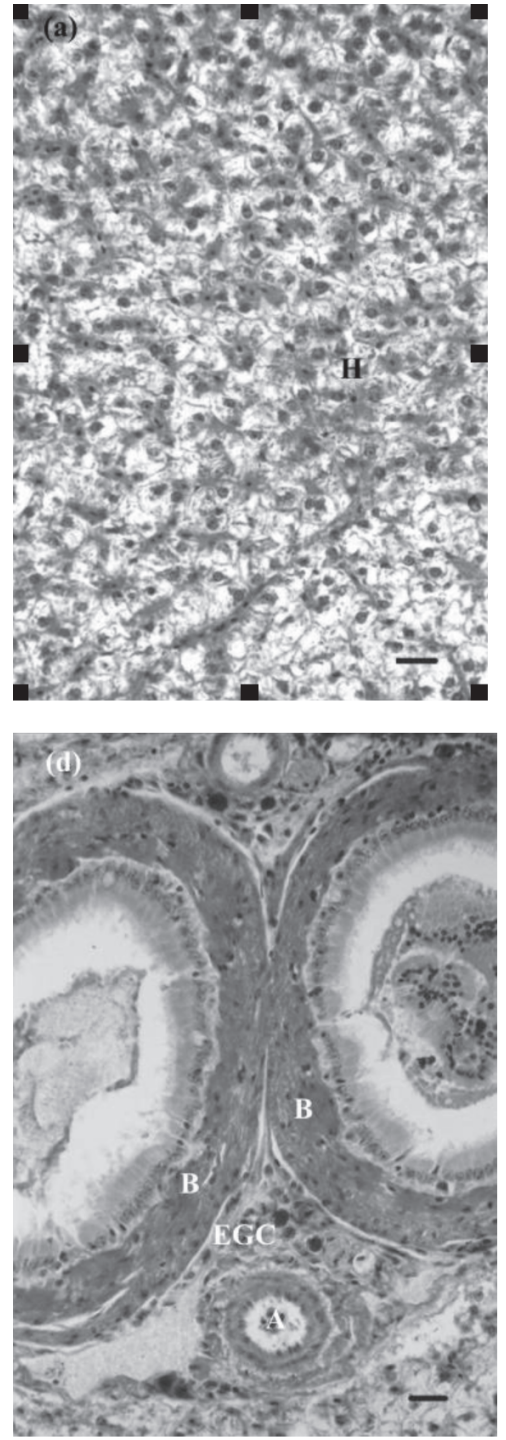
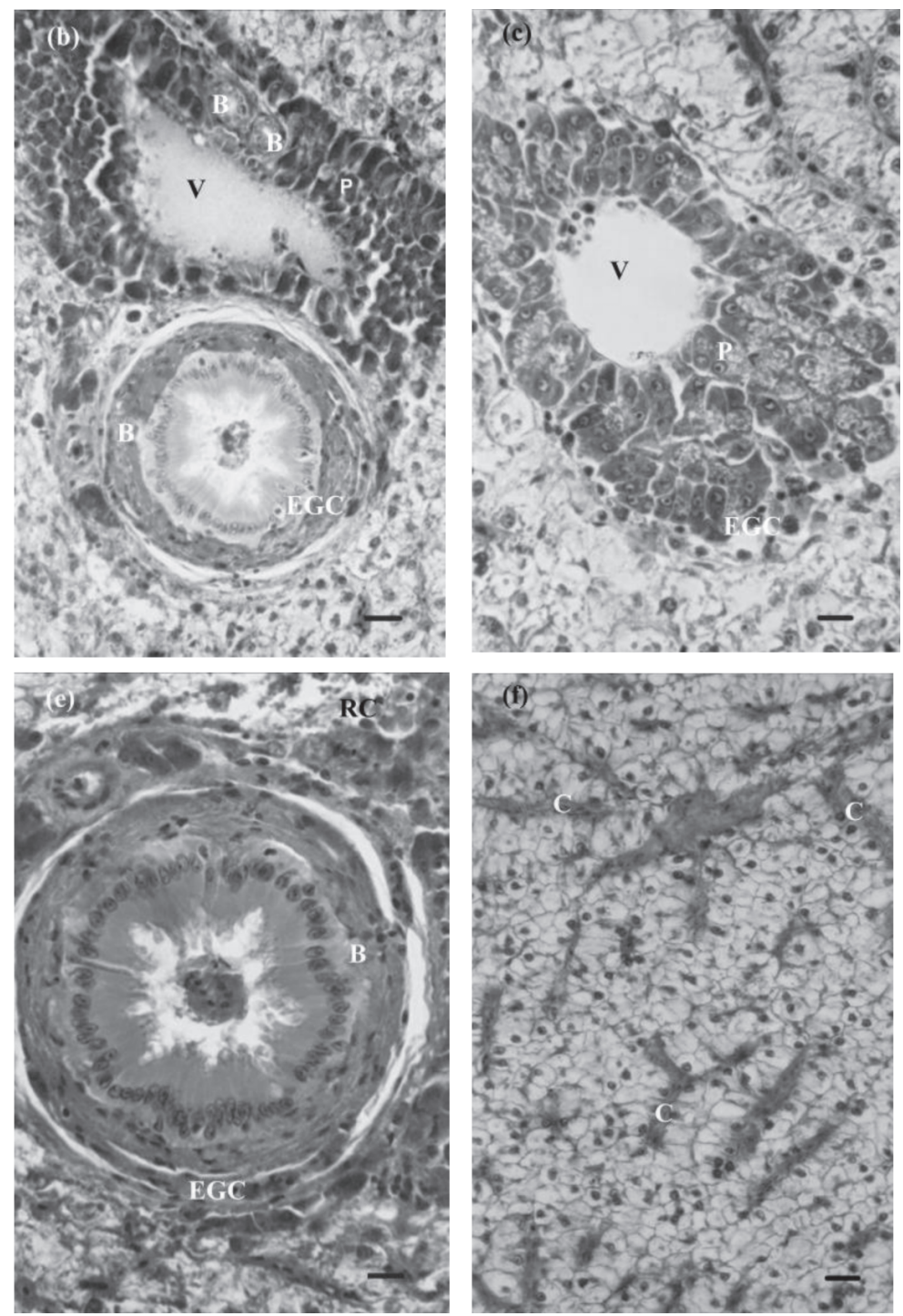

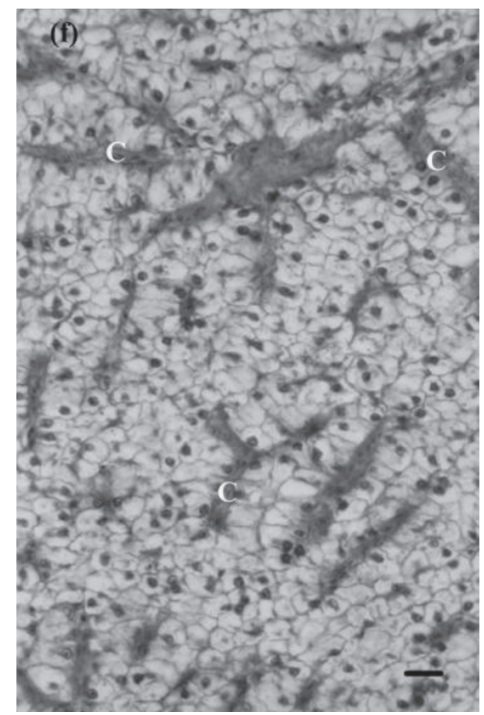

Figure 4: Hepatic sections of hepatocytes from the fishes which received the chlorophorm fraction. (a) Hepatocytes with apparent volume reduction and eosinophilic aspect. $\left(70 \mathrm{mgkg}^{-1}\right)$. (b) Ruptured hepatocytes, rounded and apparent reduction in number of hepatocyte nuclei. Presence of biliary ducts in different sizes with associated EGCs and altered pancreocytes surrounding central vein (70 $\left.\mathrm{mgkg}^{-1}\right)$. (c) EGCs associated to pancreocytes $\left(280 \mathrm{mgkg}^{-1}\right)$. (d) Biliary ducts and arterioles with associated EGCs $\left(70 \mathrm{mgkg}^{-1}\right)$. (e) Biliary duct and arteriole with associated EGCs $\left(70 \mathrm{mgkg}^{-1}\right)$. (f) Congested and dilated capillaries $\left(140 \mathrm{mgkg}^{-1}\right)$. HE [(a), (e), (f)]. Masson's trichrome [(b), (c), (d)]. $\mathrm{A}=$ arteriole; $\mathrm{V}=$ vein; $\mathrm{EGC}=$ eosinophilic granular cell $; \mathrm{H}=$ hepatocyte $; \mathrm{P}=$ pancreocyte $\mathrm{C}=$ capillary; B = biliary duct. $\mathrm{Bar}=50 \mu \mathrm{m}[(\mathrm{a}),(\mathrm{b}),(\mathrm{d}),(\mathrm{f})]$. Bar $=30 \mu \mathrm{m}[(\mathrm{c}),(\mathrm{e})]$. 
The hepatopancreas of the Nile tilapia control group in this study were normal, presenting tracts described in detail by Figueiredo-Fernandes et al. (2007a). According to these authors, the portal tract that enters the hilum, known as PVBAT (pancreatic-venous biliary arteriolar tract), is attached to the pancreocytes, presenting an axially located afferent vein, biliary $\operatorname{duct}(\mathrm{s})$ and small arterioles. The P-VBAT gradually disappears through the front (afferent) pole of the liver. These tracts ramify and originate new types of tracts that may carry one type of element (vascular or biliary) or pairs with all their possible
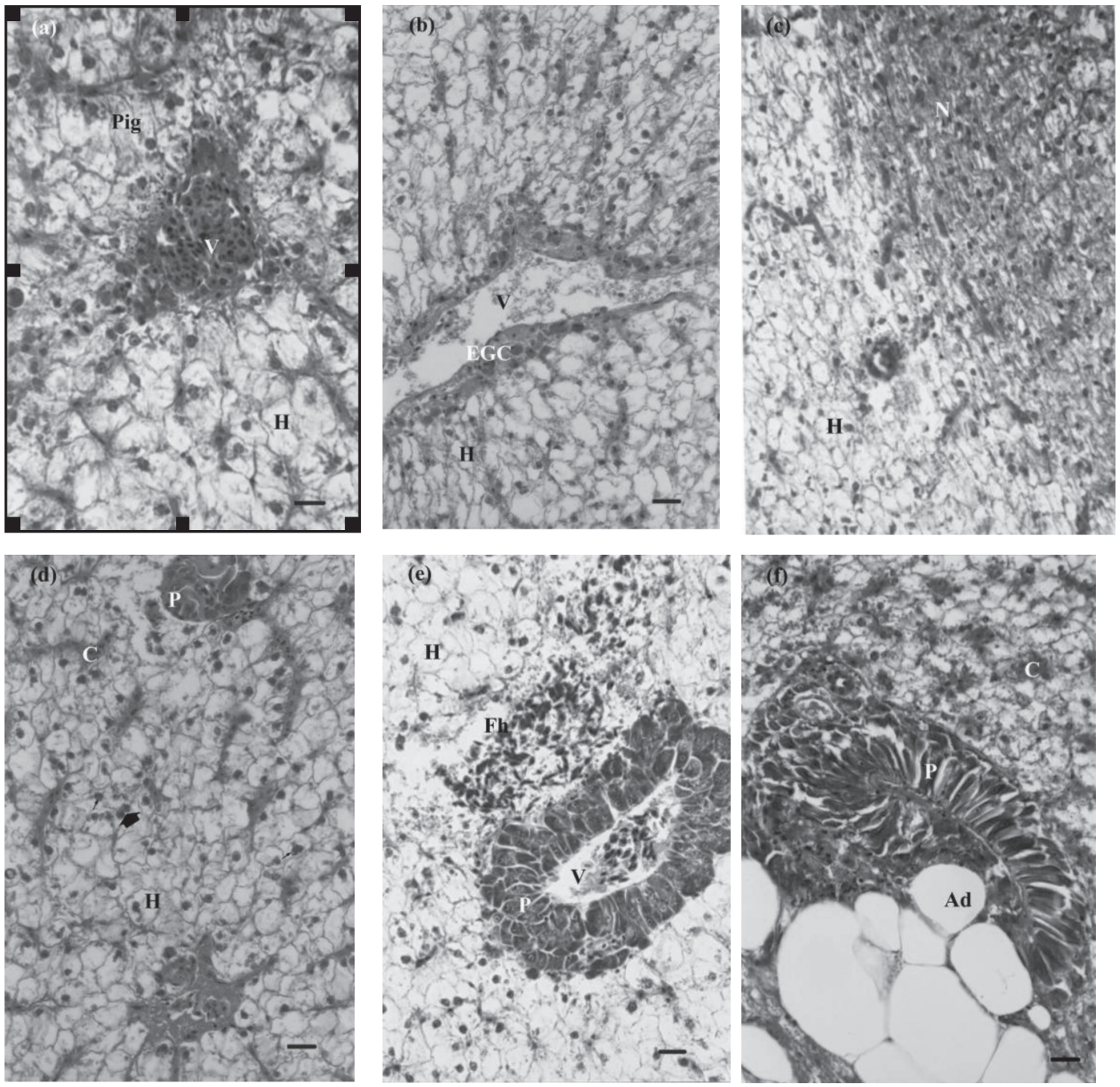

Figure 5: Hepatic sections of the tilapias which received the hexanic fraction. (a) Rounded hepatocytes with apparent increase in volume, irregular walls, some with greenish pigments in the interior $\left(280 \mathrm{mgkg}^{-1}\right)$. (b) Apparent reduction in the number of hepatocyte nuclei, picnotic nuclei. Presence of EGCs associated to the central vein and dilated and congested capillaries $\left(140 \mathrm{mgkg}^{-1}\right)$. (c) Necrosis spot $\left(280 \mathrm{mgkg}^{-1}\right)$. (d) Free polimorphonuclears (smaller arrow), plasmocytes (larger arrow) $\left(140 \mathrm{mgkg}^{-1}\right)$. (e) Hemorrhagic spot $\left(280 \mathrm{mgkg}^{-1}\right)$. (f) Altered pancreocytes with associated adipocytes $(280 \mathrm{mg} / \mathrm{kg})$. HE [(a), (b), (c), (d), (f)]. Masson's trichrome (e). Bar = $50 \mu \mathrm{m}$ [(b), (c), (d), (e), (f)]. Bar = $30 \mu \mathrm{m}$ (a). 
combinations. Most tracts have afferent veins and pancreocytes, forming P-VT (pancreatic-venous tract), P-VBT (pancreatic-venous biliary tract) and PVAT (pancreatic-venous arteriolar tract).

In comparison to mammals, fish hepatocytes tend to be more vacuolized, due to a relatively higher lipid and/or glycogen content as noted in this study (Gingerich, 1982, Ferguson, 1989). Few aggregated melanomacrophages (MMs) were noted in the livers analyzed in both the control group and the experimental groups. According to Fulop and McMillan (1984) and Herraez and Zapata (1986), MMs are constitutive cells in the normal liver and serve as repositories for products in the cellular membrane and for erythrocyte breakdown.

The number of RCs associated with pancreocytes increased in the group that received the crude extract, which may be due to an inflammatory response to one or more irritant components in this extract since, according to Dezfuli et al. (2000), RCs play an important role in the inflammatory response in fish and their recruitment could be regulated by chemical signals emitted by the EGCs. The structural characteristics of RCs are very similar to those found in leukocytes and epithelial cells and could be part of the inflammatory reaction system in the fish.

Different quantities of attached EGCs were identified in the hepatic sections of all the experimental groups and a leukocytic infiltrate was noted in all three fractions. The EGCs are mononuclear and contain protruding eosinophilic granules. These cytochemical characteristics and their involvement in pathological reactions have led to the suggestion that teleost EGCs are analogous to mammalian mast cells and are involved in defense mechanisms. Matsuyama and Iida (1999) noted that the tilapia EGCs degranulated rapidly after stimulation and that there was a correlation between EGC degranulation and neutrophil infiltration in the inflammatory site, as noted in mammals. Coimbra et al. (2007) also diagnosed an increase in the number of EGCs among the hepatocytes and near the blood vessels in
Nile tilapias exposed to Endosulphan insecticide in their diet, suggesting this may be a defense mechanism reaction to overcome the negative effects of Endosulphan.

Swollen vacuolized hepatocytes with irregular and occasionally ruptured walls, presenting central nuclei, were noted in the tilapias that received the crude extract and ethyl acetate and hexane fractions in all the concentrations. According to Wolf and Wolf (2005) fish liver exposure to toxic agents may result in the accumulation of lipid droplets or glycogen. Vacuolization by lipids or glycogen can cause swelling in hepatocytes; yet Hinton et al. (1992) identified three additional potential causes for hepatocellular swelling: proliferation of organelles (hipertrophia); mitotic division failure in the sublethaly affected hepatocytes (megalocytosis) and vacuolar increase in the endoplasmatic reticulum cistern (hydropic degeneration).

Hepatocyte hypertrophy was noted in rainbow trout simultaneously exposed to Endosulphan and Disulphoton (Arnold et al., 1995) and in Nile tilapia liver exposed to a $33 \mathrm{ppm}$ concentration of Roundup ${ }^{\circledR}$, which, in addition to swelling, also presented vacuoles in the cytoplasm, cell membrane degeneration and a leukocytic infiltrate (Jiraungkoorskul et al., 2002). Similar results were described by Coimbra et al. (2007) in Nile tilapias exposed to Endosulphan insecticide in their feed, where hepatic lesions and an increase in hepatic vacuolization were noted. Shaw and Handy (2006) noted hepatic morphological alterations with a few small hemorrhagic spots and an increase in hepatocyte lipid storage in Nile tilapias exposed to copper in their feed.

On the other hand, the tilapias that received the chloroform fraction exhibited shrunken hepatocytes. According to Ferguson (1989) glycogen or lipid loss may occur as a direct intoxication effect or subsequent to body reduction, a condition caused by inanition, stress or simultaneous disease. In this regard, FigueiredoFernandes et al. (2006) noted that Nile tilapias exposed to concentrations of 
Mancozed equal to or higher than $1.0 \mathrm{mgL}^{-1}$ presented gradual hepatocytic glycogen depletion.

The rare hepatocyte necrosis noted in the group that received the ethyl acetate fraction can be compared to the results obtained by Ferguson (1989) and Boorman et al. (1997), supposedly a common pathological response in toxin-exposed fish liver. Others, such as Figueiredo-Fernandes et al. $(2007 b)$, noted that Nile tilapias exposed to copper presented hepatocellular necrosis, hepatic parenchyma presenting small eosinophilia and an increase in cytoplasmic vacuolization. These data suggest that the ethyl acetate fraction is noxious to tilapia hepatocytes.

The hepatic sections of the fish that received the chloroform and hexane fractions presented an apparent reduction in the number of hepatocyte nuclei in some regions. Similar alterations were described by Figueiredo-Fernandes et al. (2007b) in fish exposed to increasing copper concentrations.

The hepatic capillary dilation verified in the tilapias that were administered the $E$. uniflora crude ethanol extract and all the fractions is in accordance with the results described by Consolini et al. (1999). These authors concluded that the. E uniflora aqueous crude extract peritoneally administered to normotense rats caused direct vasodilation. These facts could justify the popular use of E. uniflora as an antihypertensive drug.

This study concludes that the E. uniflora crude extract and the ethyl acetate, chloroform and hexane fractions induced vasodilation, vascular congestion and some toxicity due to the presence of EGCs, RCs, leukocytic infiltrate and rare focal necrosis. Since this plant is used popularly as an antihypertensive drug, the vasodilatory action noted in this study confirms this use, yet further studies using smaller doses of the crude ethanol extract and fractions are necessary to attempt reduction of the toxic effects of this plant and evaluate its vasodilatory effect.

The Nile tilapia proved to be a satisfactory model for screening plant products.

\section{ACKNOWLEDGEMENTS}

The authors thank the Fundação de Apoio à Pesquisa (FUNAPE/UFG), the Faculdade de Farmácia /UFG, the Instituto de Ciências Biológicas/UFG, the Department of Animal Production, School of Veterinary Medicine, UFG and would like to thank Sharon Lois Vinaud for the translation into English.

\section{REFERENCES}

ALICE CB, VARGA VMF, SILVA GAAB, SIQUEIRA NCS, SCHAPOVAL EES, GLEYE J, HENRIQUES AT (1991) Screening of plants used in south Brazilian folk medicine. J Ethnopharmacol 35: 165-171

ARNOLD H, PLUTA HJ, BRAUNBECK T (1995) Simultaneous exposure of fish to endosulfan and disulfoton in vivo: ultrastructural, stereological and biochemical reactions in hepatocytes of male rainbow trout (Oncorhynchus mykiss). Aquatic Toxicol 33: 1743

BANDONI AL, MENDIONDO ME, RONDINA RVD, COUSSIO JD (1972) Survey of Argentine medicinal plants. I. Folklore and phytochemical screening. Lloydia 35: 69-80

BOORMAN GA, BOTTS S, BUNTON TE, FOURNIE JW, HARSHBARGER JC, HAWKINS WE, HINTON DE, JOKINEN MP, OKIHIRO MS, WOLFE MJ (1997) Diagnostic criteria for degenerative, inflammatory, proliferative nonneoplastic and neoplastic liver lesions in medaka (Oryzias latipes): consensus of a National Toxicology Program Pathology Working Group. Toxicol Pathol 25: 202-210

BRASIL (1995) Ministério da Agricultura, do Abastecimento e da Reforma Agrária. Sistema de Análise de Riscos e Pontos Críticos na Indústria da Pesca: manual de procedimentos. Versão preliminar. Rio de Janeiro: SENAI/DN/DET

CASTAGNOLLI N (1992) Piscicultura de água doce. Jaboticabal: FUNEP. pp: 81-86

COIMBRA AM, FIGUEIREDO-FERNANDES A, REISHENRIQUES MA (2007) Nile tilapia (Oreochromis niloticus), liver morphology, CYP1A activity and thyroid hormones after Endosulfan dietary exposure. Pestic Biochem Physiol 89: 230-236

CONSOLINI AE, BALDINI OA, AMAT G (1999) Pharmacological basis for the empirical use of Eugenia uniflora L. (Myrtaceae) as antihypertensive. J Ethnopharmacol 66: 33-39

CONSOLINI AE, SARUBBIO MG (2002) Pharmacological effects of Eugenia uniflora (Myrtaceae) aqueous crude extract on rat' heart. J Ethnopharmacol 81: 57-63

DEZFULI BS, SIMONI E, ROSSI R, MANERA M (2000) Rodlet cells and other inflammatory cells of Phoxinus phoxinus infected with Raphidascaris acus (Nematoda). Dis Aquat Org 43: 61-69

EL-ELAIMY IA, SAKR SA, EL-SAADANY MM, GABR SA (1993) Electron Microscopic study of the liver of tilapia nilotica exposed to neopybuthrin. Bull Environ Contam Toxicol 50: 682-688

FERGUSON HW (1989) Systemic Pathology of Fish: A Text and Atlas of Comparative Tissue Responses in Diseases of Teleosts. Ames, IA: Iowa State University Press. 263 pp 
FERRI PH (1996) Química de Produtos Naturais: Métodos Gerais. In: DI STASI LC (ed) Plantas Medicinais Arte e Ciências. Um Guia de Estudo Interdisciplinar. São Paulo: Editora Universidade Estadual Paulista. pp: 129. 156

FIGUEIREDO-FERNANDES AM, FONTAÍNHASFERNANDES AA, MONTEIRO RAF, REISHENRIQUE MA, ROCHA E (2006) Effects of the fungicide Mancozed on liver structure of Nile tilápia, Oreochromis niloticus: Assessment and quantification of induced cytological changes using qualitative histopathology and the stereological point-sampled intercept method. Bull Environ Contam Toxicol 76: 249-255

FIGUEIREDO-FERNANDES AM, FONTAÍNHASFERNANDES AA, MONTEIRO RAF, REISHENRIQUE MA, ROCHA E (2007a) Spacial relationships of the intrahepatic vascular-biliary tracts and associated pancreatic acini of Nile tilapia, Oreochromis niloticus (Teleostei, Cichlidae): A serial section study by light microscopy. Ann Anat 189: 17-30

FIGUEIREDO-FERNANDES A, FERREIRA-CARDOSO JV, GARCIA-SANTOS S, MONTEIRO SM, CARROLA J, MATOS P, FONTAÍNHASFERNANDES A (2007b) Histopathological changes in liver and gill epithelium of Nile tilapia, Oreochromis niloticus, exposed to waterborne copper. Pesq Vet Bras 27: 103-109

FULOP GMI, MCMILLAN DB (1984) Phagocytosis in the spleen of the sunfish Lepomis spp. J Morphol 179: 17595

GINGERICH WH (1982) Hepatic toxicology of fishes. In: Weber LJ (ed) Aquatic Toxicology. New York: Raven Press. pp: 55-105

HEIN G, PARIZOTTO MLV, BRIANESE RH (2004) Tilápia: Referência modular para o Oeste do Paraná. Agricultor familiar, semi-intensivo, tanques escavados, clima Cfa. Paraná: Redes. Referências para agricultura familiar. $27 \mathrm{pp}$

HERRAEZ MP, ZAPATA AG (1986) Structure and function of the melanomacrophage centres of the goldfish Carassius auratus. Vet Immunol Immunopathol 12: 117-26

HINTON DE, BAUMANN PC, GARDNER GR, HAWKINS WE, HENDRICKS JD, MURCHELANO RA, OKIHIRO MS. (1992) Histopathologic markers. In: HUGGETT R, KIMERLE R, MEHRLE P, BERGMAN H (eds) Biomarkers: Biochemical, Physiological and Histological Markers of Anthropogenic Stress. Boca Raton: Lewis Publishers. pp. $155-209$

JIRAUNGKOORSKUL W, UPATHAM ES, KRUATRACHUE M, SAHAPHONG S, VICHASRIGRAMS S, POKETHITIYOOK P (2002) Histopathological Effects of Roundup, a Glyphosate Herbicide, on Nile tilapia (Oreochromis niloticus). Science Asia 28: 121-127

MATSUYAMA T, IIDA T (1999) Degranulation of eosinophilic granular cells with possible involvement in neutrophil migration to site of infammation in tilapia. Dev Comp Immunol 23: 451-457

OETTERER M (2004) Tecnologias emergentes para processamento do pescado produzido em piscicultura. In: CYRINO JEP, URBINATI EC, FRACALOSSI DM, CASTAGNOLLI N (eds) Tópicos especiais em piscicultura de água doce tropical intensiva. São Paulo: TecArt. . pp: 481-500

SANCHOTENE MCC (1985) Frutíferas nativas úteis à fauna na arborização urbana. Porto Alegre: FEPLAM pp.176-179

SANO SM, ALMEIDA SP (1998) Cerrado: ambiente $e$ flora. Planaltina: EMBRAPA-CPAC. 556p

SHAW BJ, HANDY RD (2006) Dietary copper exposure and recovery in Nile tilapia, Oreochromis niloticus. Aquatic Toxicol 76, 111-121

SOUZA GC, HAAS APS, VON POSER GL, SCHAPOVAL EES, ELISABETSKY E (2004). Ethnopharmacological studies of antimicrobial remedies in the south of Brazil. J Ethnopharmacol 90: 135-143

WOLF JC, WOLF EMJ (2005) A brief overview of nonneoplastic hepatic toxicity in fish. Toxicol Patholol 33: $75-85$ 